\title{
ANALISIS PENGATURAN TAP TRAFO PADA PT PJB INDRAMAYU 3X300 MW MENGGUNAKAN METODE PARTICLE SWARM OPTIMIZATION (PSO) UNTUK MEREDUKSI RUGI DAYA
}

\author{
Lisa Amalina Saputri*), Agung Warsito dan Susatyo Handoko. \\ Departemen Teknik Elektro, Universitas Diponegoro \\ . Prof. Sudharto, SH, Kampus UNDIP Tembalang, Semarang 50275, Indonesia \\ ${ }^{*}$ E-mail: lisaamalina@yahoo.co.id
}

\begin{abstract}
Abstrak
Pada sistem tenaga listrik terdapat beberapa penyebab yang dapat mempengaruhi nilai rugi daya antara lain panjang jaringan, diameter penghantar, pembebanan kapasitas trafo. Berdasarkan SPLN 72: 1986, besar nilai rugi daya pada suatu jaringan adalah sebesar maksimal 5\%. Salah satu cara yang dapat digunakan untuk meminimalisir nilai rugi daya adalah dengan pengaturan nilai tap trafo pada trafo. Pada PT PJB Indramayu,terdapat 23 buah trafo permakaian sendiri. Rugi sistem rata-rata adalah sebesar 5\%. Dalam tugas akhir ini, pengoptimalan pengaturan Tap trafo dilakukan dengan simulasi menggunakan metode Particle Swarm Optimization (PSO) dibantu menggunakan software MATLAB 2014a. Metode optimasi menggunakan PSO ini didasarkan pada perilaku sebuah kawanan burung. Simulasi ini dilaksanakan dengan cara pengaturan Tap trafo pada masing masing trafo. Hasil simulasi menunjukkan dengan pengaturan tap trafo pada semua trafo pada PT PJB Indramayu nilai rugi daya turun dari 20.7946 MW menjadi 20.7901MW.
\end{abstract}

Kata Kunci: rugi daya, tap trafo, PSO

\begin{abstract}
In electric power system there are several causes that can affect the value of power loss, such as network length, conductor diameter, loading of transformer capacity. Based on SPLN 72: 1986, the value of power loss in a network is at a maximum of $5 \%$. One way that can be used to minimize the value of power loss is by setting the transformer Tap value on the transformer. At PT PJB Indramayu, there are 23 pieces of own trafo. Average system loss is 5\%. In this final project, Tap transformer optimization is done by simulation using Particle Swarm Optimization (PSO) method with MATLAB 2014a software. The optimization method using PSO is based on the behavior of a flock of birds. This simulation is done by setting Tap transformer on each transformer. The simulation results showed by setting transformer tap on all transformers at PT PJB Indramayu loss of power value down from 20.7946 MW to 20.7901MW.
\end{abstract}

Keywords: losses, tap transformator, PSO

\section{Pendahuluan}

Seiring berkembangnya sistem kelistrikan, dibutuhkan peningkatan tegangan dalam penyaluran energi listrik. Peningkatan tegangan dapat dilakukan dari sisi pembangkitan, transmisi, dan distribusi untuk menciptakan sistem yang bekerja secara optimum. Kondisi optimum adalah kondisi sistem yang memiliki rugi-rugi daya minimum[1]. Pada sisi distribusi, peningkatan tegangan dapat dilakukan dengan cara mengurangi besar rugi daya saluran. Salah satu cara yang dapat digunakan untuk mendapatkan nilai rugi rugi daya minimum adalah dengan melakukan pengaturan tap trafo[2]. Tap trafo digunakan sebagai pengubah tegangan sekunder yang mempengaruhi daya reaktif. Dengan pemasangan tap trafo pada trafo distribusi, maka tegangan sekunder dapat dinaikkan maupun diturunkan. Bila nilai tegangannya dinaikkan, maka arus yang mengalir semakin kecil sehingga rugi-rugi daya juga akan kecil pula[3]. Untuk mendapatkan rugi rugi minimum diperlukan adanya metode. Metode ini memudahkan untuk mendapatkan suatu kondisi dimana sistem bekerja dengan maksimal sesuai dengan objek yang dioptimisasi. Dalam hal ini adalah mengoptimalkan pengaturan tap trafo.

Beberapa penelitian terdahulu menyatakan bahwa penggunaan tap trafo dapat meminimalisasi nilai rugi-rugi daya [4], sementara penyelesaian mengenai optimasi ini dapat dilakukan menggunakan beragam metode optimasi[5][6][7]. Salah satu cara yang dapat digunakan untuk meminimalisasi rugi daya adalah dengan menggunakan metode pengubahan Tap trafo [8]. 
Salah satu metode optimasi yang dapat menghitung secara optimal adalah Particle Swarm Optimization (PSO) [6,9]. PSO ini didasarkan pada perilaku sebuah kawanan burung [10]. Oleh karena itu, penulis melakukan penelitian untuk menyelesaikan permasalah rugi rugi daya dengan pengaturan tap trafo pada trafo dengan bantuan metode Particle Swarm Optimization (PSO) menggunakan Software MATLAB 2014a.

\section{Metode}

Perancangan program simulasi optimasi ini menggunakan software MATLAB R2014a dengan metode Particle Swarm Optimization (PSO). Program simulasi ini dirancang dalam 3 tahap utama,yaitu tahap pertama menentukan kondisi awal sistem, tahap kedua optimasi penggunaan nilai tap trafo, dan tahap ketiga menampilkan kondisi setelah penggunaan tap trafo. Prosedur pembuatan simulasi ini ditunjukkan pada diagram alir Gambar 1.

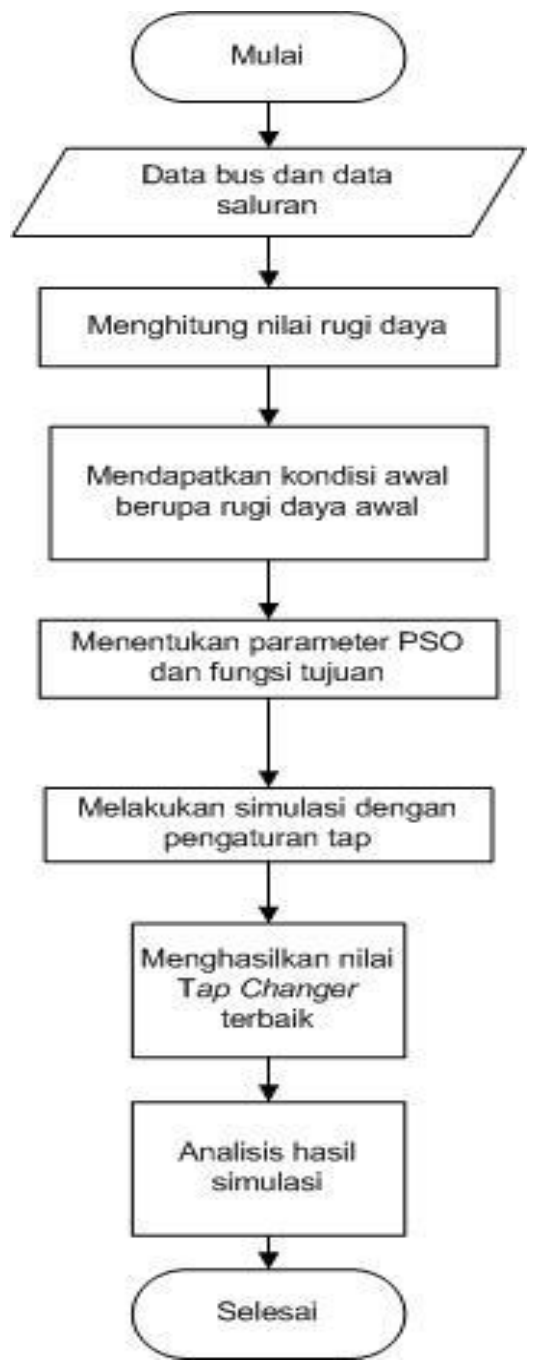

Gambar 1. Diagram Alir penelitian

\subsection{Penginputan data}

Data yang diperlukan untuk simulasi meliputi data saluran dan data bus dari sistem yang akan dianalisa, dimana data tersebut digunakan untuk menghitung aliran daya menggunakan metode Newton-RhaPSOn sehingga diketahui kondisi awal sistem sebelum menentukan nilai tap trafo. Setelah mendapatkan kondisi awal dari sistem, tentukan jumlah trafo yang akan di optimasi nilai tap trafonya.

Untuk memperoleh nilai tap trafo yang optimal perlu diinputkan beberapa persyaratan yang akan ditetapkan dalam proses optimisasi meliputi batas tegangan maksimum dan minimum yang diperbolehkan pada tiap bus, nilai batas daya aktif dan reaktif dari generator yang digunakan pada sistem.

Parameter PSO yang diperlukan meliputi ukuran swarm, maksimal iterasi yang diperbolehkan, nilai $\mathrm{C} 1$ dan $\mathrm{C} 2$, inertia weight. Dimana nilai-nilai tersebut akan mempengaruhi waktu yang dibutuhkan dan ketelitian nilai yang dihasilkan dari proses optimisasi.

\subsubsection{Proses Optimasi}

Tabel 1 menjelaskan tentang analogi PSO yang digunakan pada simulasi ini.

Tabel 1. Analogi PSO

\begin{tabular}{l|l}
\hline \multicolumn{1}{c|}{ Parameter PSO } & \multicolumn{1}{c}{ Penjelasan } \\
\hline Swarm & Kandidat trafo yang akan di optimisasi \\
Particle & Iterasi \\
Pbest & Nilai Losses terbaik dari setiap particle \\
Gbest & Nilai Losses terbaik dari setiap iterasi \\
Inertia Weight & Konstanta perlambatan \\
Velocity & Kecepatan partikel mengiterasi \\
\hline
\end{tabular}

\section{A. Inisialisasi posisi dan kecepatan partikel}

Pada tahap ini bertujuan untuk membangkitkan sebuah kawanan partikel secara random yaitu kandidat bus yang akan diatur tap nya. Dimana banyaknya partikel yang dibangkitkan sesuai dengan ukuran swarm yang telah ditentukan sebelumnya. Partikel ini untuk selanjutnya akan dikenal dengan posisi dari partikel. Adapun persamaan untuk posisi partikel sebagai berikut :

$X_{i r+1}=X_{i r}+V_{i r+1}$

Nilai kecepatan dari setiap partikel yang dibangkitkan pada kondisi awal dihitung dengan menggunakan persamaan seperti berikut :

$$
\begin{gathered}
V_{i r+1}=w * V_{i r}+c 1 . \text { rand } *\left(P_{\text {best }_{i r}}-X_{i r}\right) \\
+c 2 . \text { rand } *\left(G_{\text {best }_{i r}}-X_{i r}\right)
\end{gathered}
$$




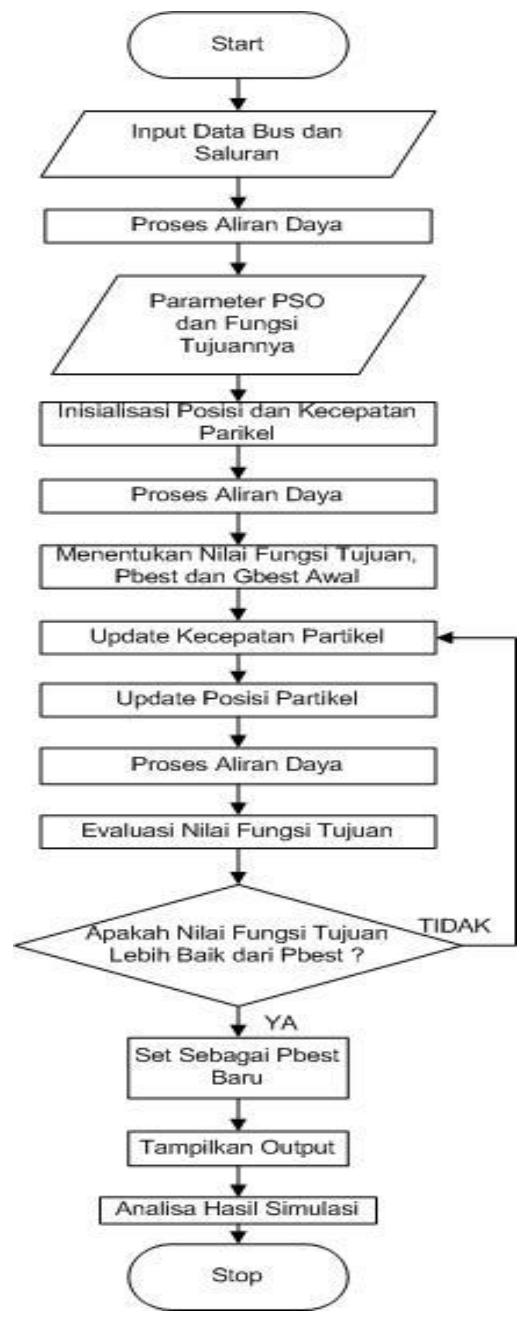

Gambar 2. Diagram Alir Pembuatan Program

\section{B. Fungsi Tujuan}

Diagram alir dari metode PSO ditunjukkan pada Gamabr 2. Pada program simulasi ini, fungsi tujuan untuk proses optimisasi dapat dirumuskan dalam bentuk matematis sebagai berikut :

TotalLoss $=\min \left[\operatorname{Re}\left[\sum_{i=1}^{n} \sum_{j=1}^{n} S_{L_{i j}}\right]\right]$

\section{Update kecepatan dan posisi}

Kecepatan dan posisi dari setiap partikel akan diubah mendekati nilai terbaik dari fungsi tujuan yang diperoleh dari proses sebelumnya. Hal ini bertujuan agar sekawanan partikel menuju satu hasil nilai tujuan yang terbaik.

\section{Proses aliran daya}

Pada tahap ini nilai tap trafo yang dihasilkan dari tiap posisi partikel ditempatkan sesuai kandidat bus yang ada untuk kemudian dilakukan proses aliran daya untuk mengetahui nilai tegangan pada tiap bus (Voltage Magnitude \% ) serta daya yang dibangkitkan generator telah sesuai dengan persyaratan yang ditetapkan. Dalam proses ini pula akan diperoleh jumlah rugi daya aktif yang berkurang dan akan digunakan dalam perhitungan nilai fungsi tujuan.

\section{E. Evaluasi fungsi tujuan}

Setiap partikel yang sudah mengalami perubahan posisi dan kecepatan dilakukan evaluasi pada fungsi tujuan untuk menentukan partikel dengan nilai tujuan terbaik yang akan ditetapkan sebagai Gbest, sedangkan untuk menentukan Pbest dengan membandingkan nilai fungsi tujuan dari posisi sekarang dengan Pbest dari iterasi sebelumnya untuk setiap partikel.

\section{F. Stopping criteria}

Penghentian proses iterasi dari PSO dapat dilakukan dengan 2 cara :

- Mengecek nilai dari selisih hasil fungsi tujuan sekarang dengan hasil fungsi tujuan sebelumnya.

- Pembatasan iterasi (maksimal iterasi). Cara ini digunakan apabila selisih niai fungsi tujuan tidak mencapai konvergen maka iterasi akan berhenti pada iterasi maksimum.

\section{Hasil dan Analisis}

Melalui pengujian ini dimaksudkan agar mendapatkan nilai tap trafo yang optimal untuk meminimalisir nilai rugirugi daya. Paramete PSO yang digunakan adalah berdasarkan hasil pengujian sebelumnya. Nilai parameter yang digunakan untuk optimasi penggunaan Tap trafo untuk pengujian sistem ini ditunjukkan pada Tabel 2 .

\subsection{Pengujian Ukuran Populasi dan Jumlah Iterasi}

Ukuran populasi adalah banyak kombinasi angka yang digunakan dalam optimasi. Penentuan ukuran populasi penting karena kombinasi yang ada mempengaruhi hasil optimasi PSO. Dalam pengujian ini nilai ukuran populasi dilakukan perulangan proses optimasi sebanyak 2 kali dengan nilai iterasi yang berbeda untuk membandingkan hasil nilai tujuan. Nilai parameter lain yang dibutuhkan dalam proses optimasi dapat dilihat pada Tabel 2.

Tabel 2. Parameter optimasi yang digunakan untuk penentuan ukuran populasi dan jumlah iterasi

\begin{tabular}{lll}
\hline Jenis Parameter & \multicolumn{1}{c}{ Parameter } & Nilai \\
\hline Parameter PSO & Jumlah iterasi & $100,200,300$ \\
& Ukuran Populasi & 5,10 \\
& C1 & 2 \\
& C2 & 1 \\
& Omin & 0,4 \\
& Omax & 0,7 \\
Syarat Sistem & Vmin & $0,1 \mathrm{pu}$ \\
& Qmin & $1,05 \mathrm{pu}$ \\
& Qmax & $0,0001 \mathrm{MVAR}$ \\
& Pmin & $7 \mathrm{MVAR}$ \\
& Pmax & $0,001 \mathrm{MVAR}$ \\
& & $10 \mathrm{MW}$ \\
\hline
\end{tabular}


Setelah dilakukan proses simulasi menggunakan variasi jumlah iterasi dan ukuran populasi yang ditentukan pada Tabel 2,

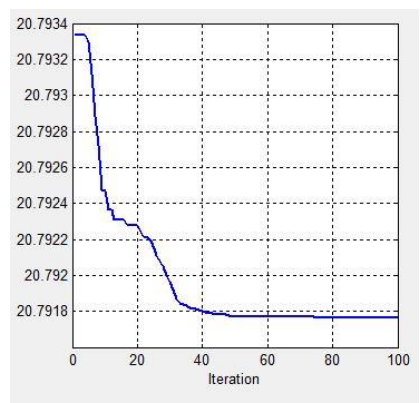

Gambar 3. Grafik hasil pengujian ke-1

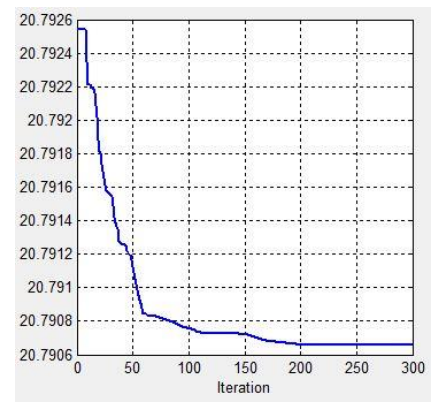

Gambar 4. Grafik hasil pengujian ke-2

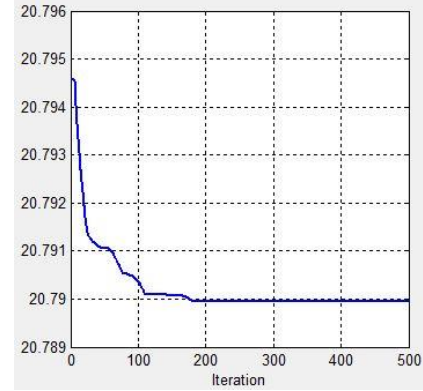

Gambar 5. Grafik hasil pengujian ke-3

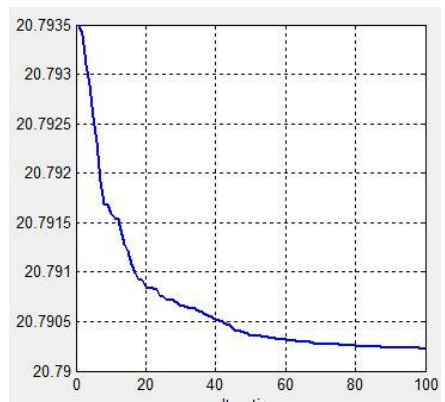

Gambar 6. Grafik hasil pengujian ke-4

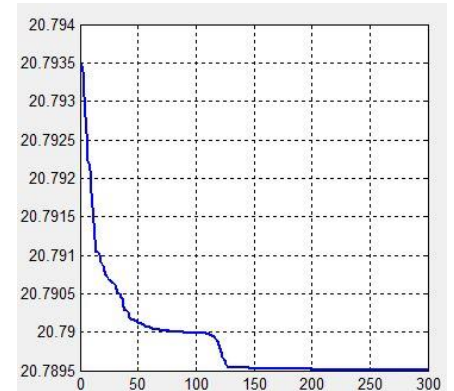

Gambar 7. Grafik hasil pengujian ke-5

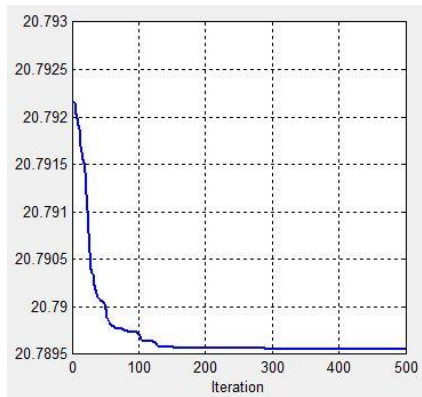

Gambar 8 Grafik hasil pengujian ke-6

Berdasarkan Gambar di atas dapat diketahui bahwa Gambar 3 dan Gambar 6 belum mencapai hasil yang konvergen sedangkan Gambar 4, Gambar 5, Gambar 7, dan Gambar 8 sudah mencapai hasil yang konvergen. Berdasarkan beberapa hasil pengujian diatas, nilai populasi yang akan digunakaan menjadi parameter optimasi adalah ukuran populasi berjumlah 10 dan jumlah iterasi sebanyak 300, karena semakin banyak ukuran populasi dan jumlah iterasi mempengaruhi tercapainya hasil yang konvergen.

\subsection{Penentuan Learning Rates (C)}

Learning rates merupakan suatu konstanta yang digunakan untuk menilai kemampuan individu (C1) dan pengaruh social kelompok (C2) yang menunjukan bobot dari posisi sebuah partikel terhadap posisi dari kelompoknya. Dalam pengujian ini, penentuan nilai $\mathrm{C} 1$ dan $\mathrm{C} 2$ dengan memvariasikan angka 0.01 (kecil), 1 (sedang), dan 2 (besar) untuk diperoleh variasi angka terbaik dalam memperoleh nilai fungsi tujuan yang minimal. Untuk nilai parameter lain yang dibutuhkan dalam proses optimasi, dapat dilihat pada Tabel 3

Tabel 3. Penentuan Parameter Learning Rates

\begin{tabular}{lll}
\hline Jenis Parameter & \multicolumn{1}{c}{ Parameter } & Nilai \\
\hline Parameter PSO & Jumlah Iterasi & 300 \\
& Ukuran Populasi & 10 \\
& C1 & $(0,01), 1,2$ \\
& C2 & $(0,01), 1,2$ \\
& Omin & 0,4 \\
Syarat Sistem & Omax & 0,7 \\
& Vmin & $0,1 \mathrm{pu}$ \\
& Vmax & $1,05 \mathrm{pu}$ \\
& Qmin & $0,0001 \mathrm{MVAR}$ \\
& Qmax & $7 \mathrm{MVAR}$ \\
& Pmin & $0,001 \mathrm{MVAR}$ \\
& Pmax & $10 \mathrm{MW}$ \\
\hline
\end{tabular}




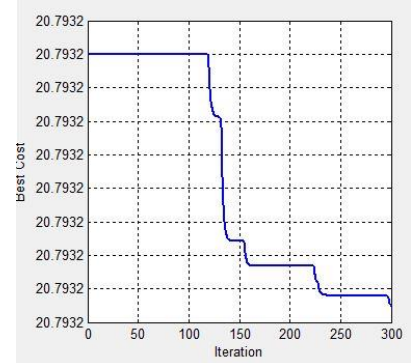

Gambar 9. Grafik hasil pengujian ke-1

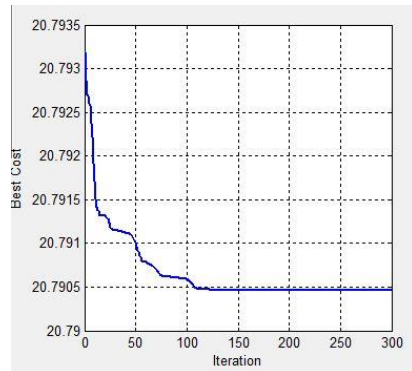

Gambar 10. Grafik hasil pengujian ke-2

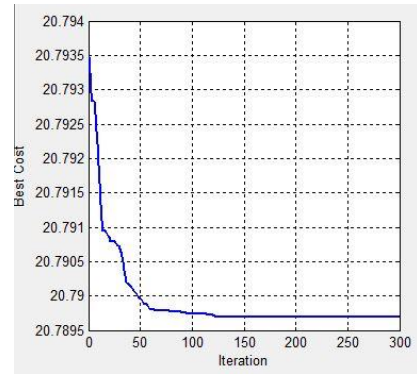

Gambar 11. Grafik hasil pengujian ke-3

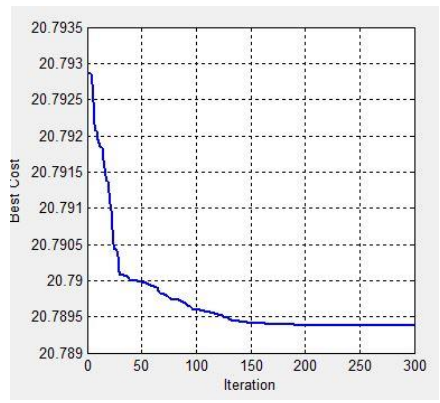

Gambar 12. Grafik hasil pengujian ke-4

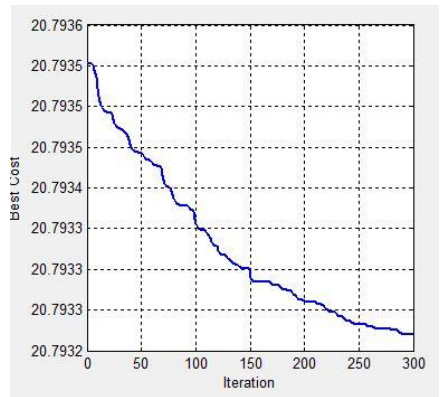

Gambar 13. Grafik hasil pengujian ke-5

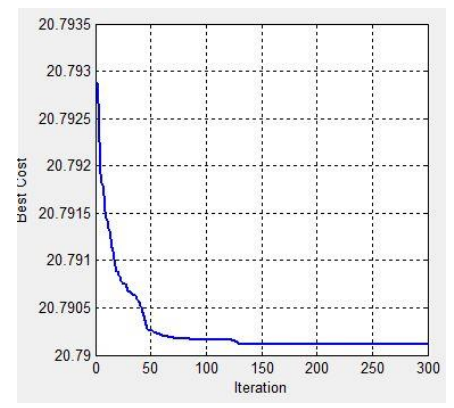

Gambar 14. Grafik hasil pengujian ke-6

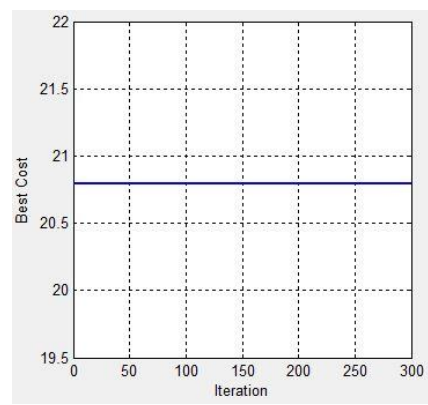

Gambar 15. Grafik hasil pengujian ke-7

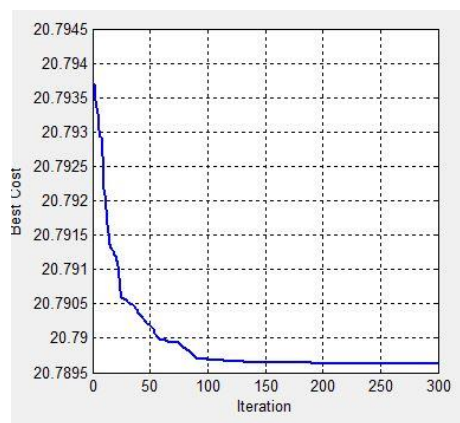

Gambar 16. Grafik hasil pengujian ke-8

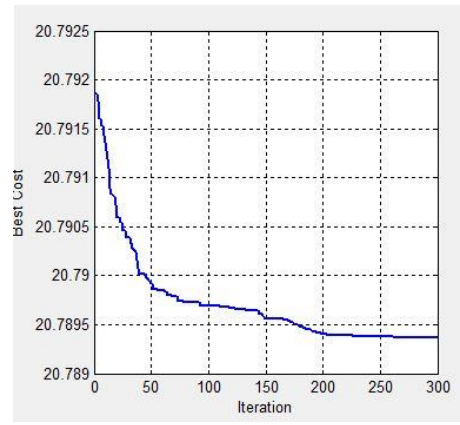

Gambar 17. Grafik hasil pengujian ke-9

Berdasarkan Gambar diatas, dapat diketahui bahwa penggunaan nilai $\mathrm{C} 1$ dan $\mathrm{C} 2$ mempengaruhi nilai fungsi tujuan dan proses iterasi yang diperlukan. Nilai C1 dan C2 mempengaruhi tingkat ketelitian pada setiap iterasi yang dilakukan, sehingga jika nilai C1 dan C2 sangat kecil maka 
akan sulit untuk mendapatkan hasil yang konvergen. Pada Gambar 10, Gambar 11, Gambar 12 dan Gambar 16 didapatkan hasil yang belum konvergen. Pada Gambar 15, grafik yang dihasilkan pada pengujian ke-6 tidak terdapat lonjakan nilai yang besar dan hasil yang dihasilkan konvergen, sehingga kombinasi $\mathrm{C} 1$ dan $\mathrm{C} 2$ yang digunkana adalah 1 dan 2.

\subsection{Penentuan Inertia Weight $(\theta)$}

Penggunaan parameter inertia weight dalam PSO adalah untuk mengontrol kecepatan dalam menentukan solusi optimum dari fungsi tujuan. Dimana rentang nilai yang digunakan biasanya kurang dari 1. Dalam pengujian ini, penentuan nilai $\theta$ adalah $0.4-0.9$ untuk diperoleh variasi angka terbaik dalam memperoleh nilai fungsi tujuan yang minimal. Untuk nilai parameter lain yang dibutuhkan dalam proses optimasi, dapat dilihat pada Tabel 4 .

Tabel 4. Penentuan Parameter Inertia Weight

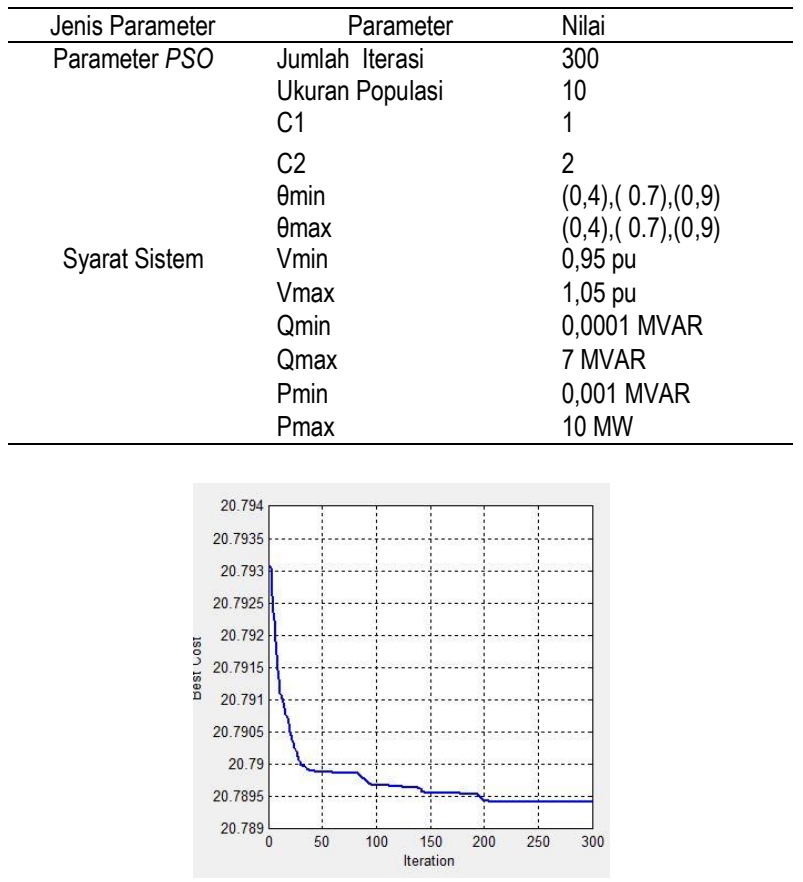

Gambar 18. Grafik hasil pengujian ke-1

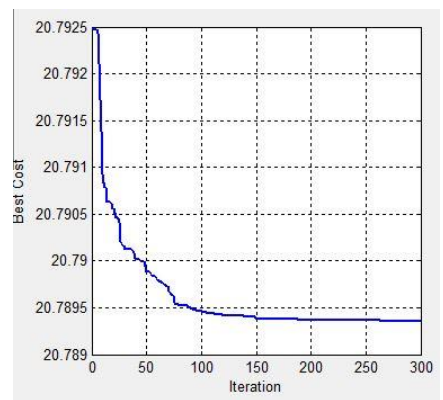

Gambar 19. Grafik hasil pengujian ke-2

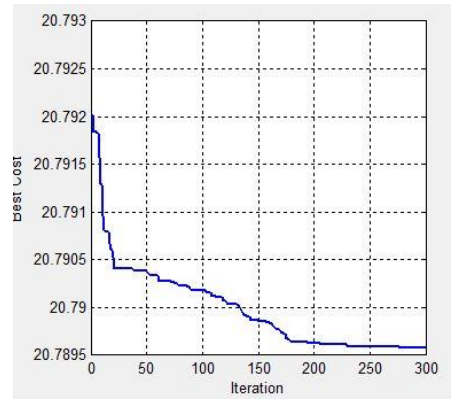

Gambar 20. Grafik hasil pengujian ke-3

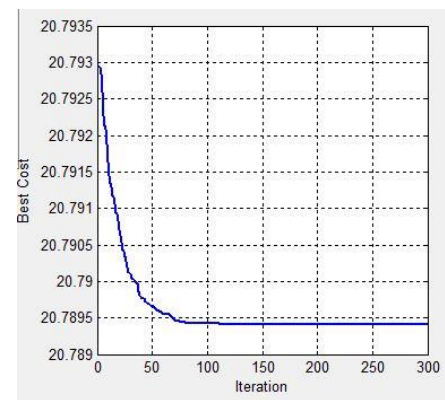

Gambar 21. Grafik hasil pengujian ke-4

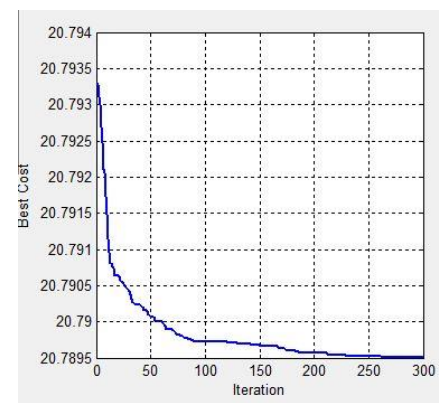

Gambar 22. Grafik hasil pengujian ke-5

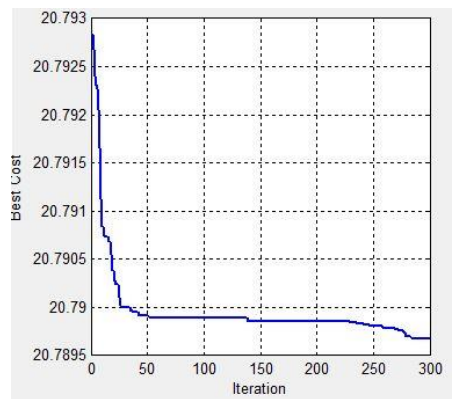

Gambar 23. Grafik hasil pengujian ke-6 


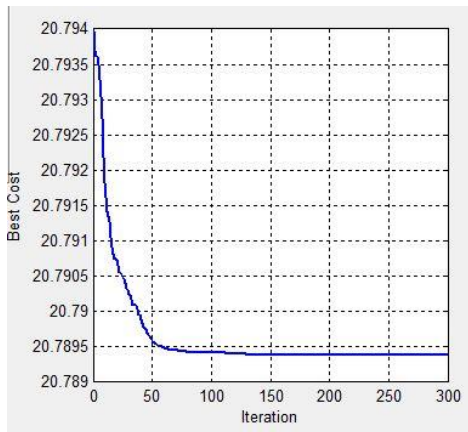

Gambar 24. Grafik hasil pengujian ke-7

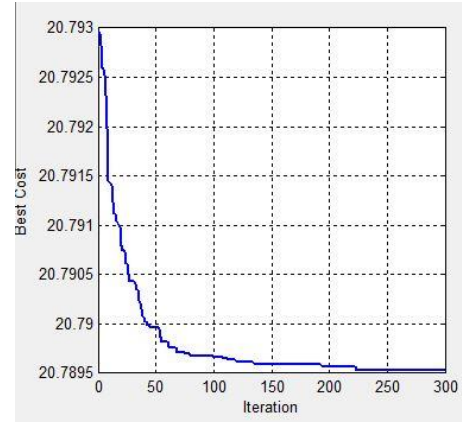

Gambar 25. Grafik hasil pengujian ke-8

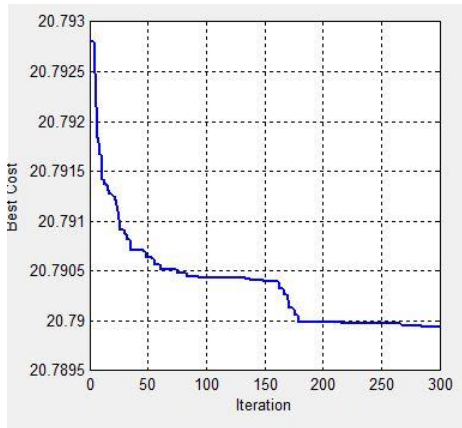

Gambar 26. Grafik hasil pengujian ke-9

Berdasarkan Grafik hasil pengujian yang ada (Gambar 1826), didapatkan bahwa pengujian ke-2, pengujian ke-3, pengujian ke-5, pengujian ke-6, dan pengujian ke-9 belum mencapai hasil konvergen sedangkan pengujian ke-1, ke4, ke-7, dan ke-8 mencapai hasil konvergen. Maka dilakukan perbandingan diantara pengujain tersebut yang menghasilkan nilai konvergen dan menghasilkan hasil fungsi tujuan terkecil adalah pengujian ke 7 , yaitu $\theta_{\text {min }}$ adalah 0.9 dan $\theta_{\max }$ adalah 0.4 .

\subsection{Hasil Pengujian Simulasi Program}

Simulasi program ini dimaksudkan agar mendapatkan hasil nilai tap trafo paling optimal berdasarkan parameter parameter yang telah ditentukan pada sub bab sebelumnya. Parameter yang digunakan untuk pengujian simulasi ditunjukkan pada Tabel 5. Setelah proses optimasi selesai maka akan mendapatkan nilai tap trafo seperti Tabel 6 .

Dari hasil tersebut, akan didapatkan grafik hasil fungsi tujuan seperti Gambar 27. Berdasarkan hasil pengujian pada Gambar 27, dapat dilihat nilai rugi daya turun dari 20.7946 MW menjadi 20.7894 MW.

Tabel 5. Parameter optimasi yang digunakan untuk pengujian sistem

\begin{tabular}{lll}
\hline Jenis Parameter & \multicolumn{1}{c}{ Parameter } & Nilai \\
\hline Parameter PSO & Jumlah Iterasi & 300 \\
& Ukuran Populasi & 10 \\
& C1 & 1 \\
& C2 & 2 \\
& Omin & 0,9 \\
Syarat Sistem & Omax & 0,4 \\
& Vmin & $0,1 \mathrm{pu}$ \\
& Vmax & $1,05 \mathrm{pu}$ \\
& Qmin & $0,0001 \mathrm{MVAR}$ \\
& Qmax & $7 \mathrm{MVAR}$ \\
& Pmin & $0,001 \mathrm{MVAR}$ \\
& Pmax & $10 \mathrm{MW}$ \\
\hline
\end{tabular}

Tabel 6. Hasil nilai tap trafo

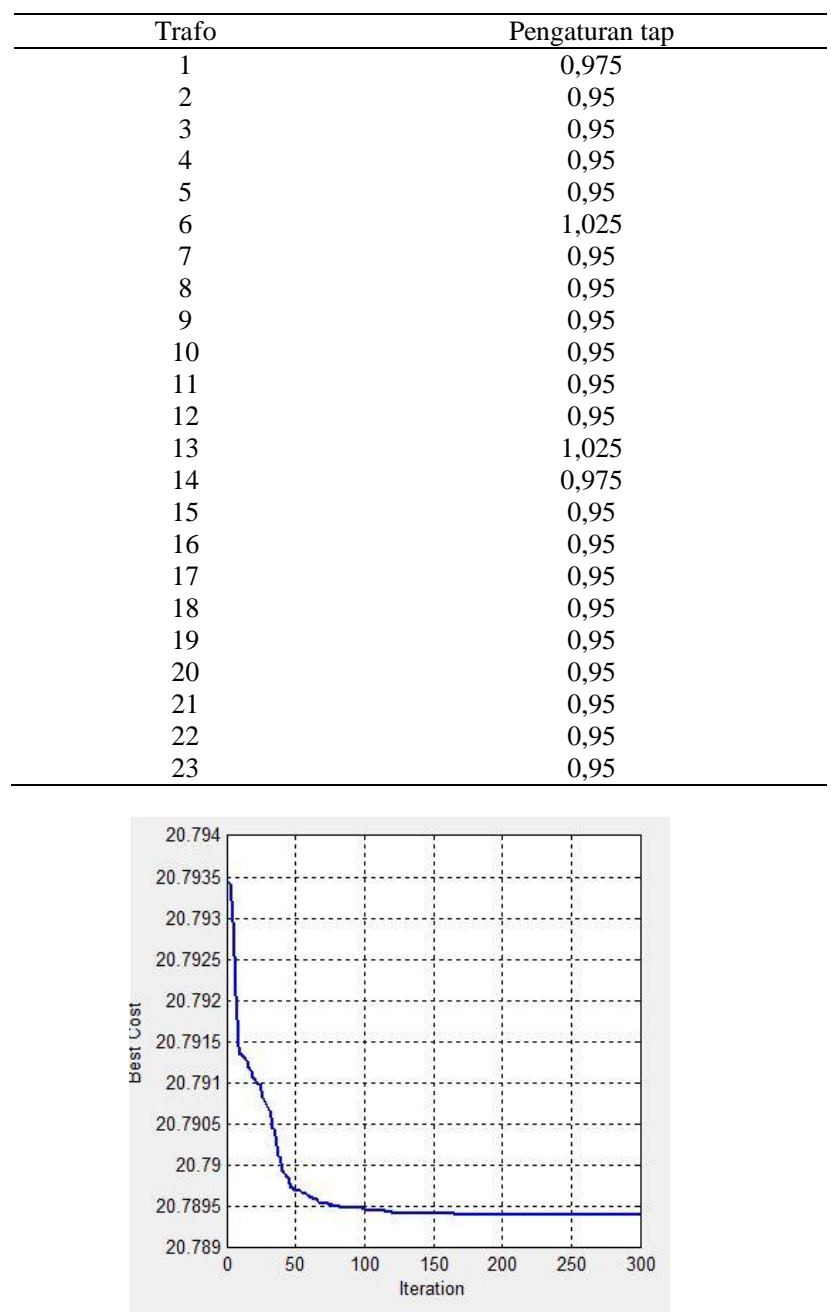

Gambar 27. Grafik nilai fungsi tujuan tiap iterasi 


\subsection{Perbandingan Sebelum dan Sesudah Optimasi}

Setelah dilakukan optimasi diperoleh hasil akhir berupa rugi rugi daya yang telah di minimalisir. Hasil perbandingan kondisi sistem sebelum dan sesudah optimasi ditunjukkan pada Tabel 7.

Tabel 7. Perbandingan sebelum dan sesudah optimasi

\begin{tabular}{lcc}
\hline \multicolumn{1}{c}{ DESKRIPSI } & SEBELUM & SESUDAH \\
\hline Rugi Daya Aktif (MW) & 20,7946 & 20,7894 \\
Rugi Daya Reaktif & 85,4292 & 85,420 \\
(MVAR) & & \\
\hline
\end{tabular}

Berdasarkan Tabel 7, dapat diketahui setelah memasukkan nilai tap trafo, kondisi sistem menjadi lebih baik. Hal ini ditunjukkan oleh tegangan terendah meningkat dari 0,9487 menjadi 0,95. Selain itu, rugi-rugi daya aktif juga menurun dari 20,7946 MW menjadi 20,7894 MWsetelah memasukkan nilai tap trafo. Selain itu, rugi daya reaktif menurun dari 85,4292 MVAR menjadi 85,420 MVAR.

Perbandingan tegangan pada tiap bus setelah dan sesudah pemasangan Tap trafo dapat dilihat pada Gambar 28 dan Gambar 29.

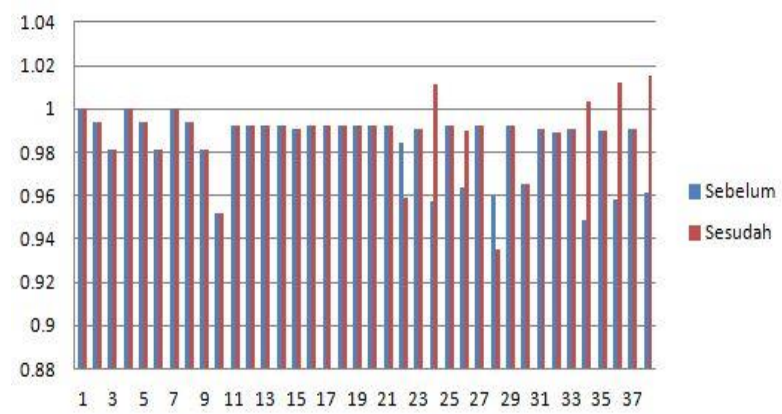

Gambar 28. Grafik perbandingan tiap bus sebelum dan sesudah pemberian nilai tap trafo (1)

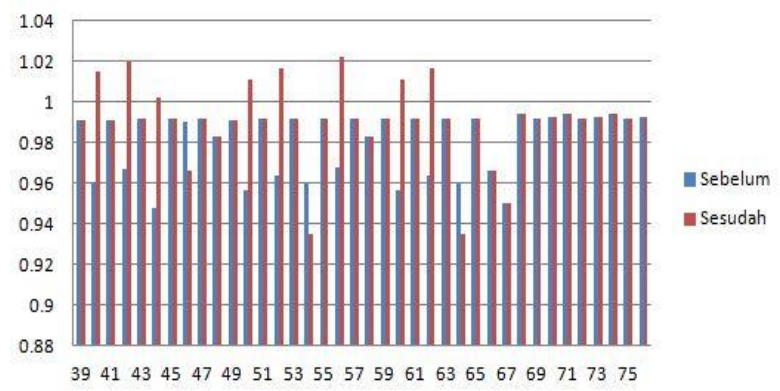

Gambar 29. Grafik perbandingan tiap bus sebelum dan sesudah pemberian nilai tap trafo 2

Berdasarkan Gambar 28 dan Gambar 29 terlihat bahwa setelah penambahan nilai Tap trafo, tegangan pada bus 22 , $24,26,28,30,32,34,36,38,40,42,44,46,48,50,52,54$, $56,58,60,62,64,66$, dan 68 mengalami peningkatan dan berada pada batas nilai yang ditentukan yaitu 0.95 dan 1.05 .

\section{Kesimpulan}

Setelah dilakukan simulasi pengoptimasian pengaturan tap trafo didapatkan kesimpulan yaitu setelah dilakukan pengoptimasian penggunaan tap trafo menggunakan metode PSO nilai tap trafo yang diperoleh dari simulasi adalah trafo 1 adalah 0,975 , trafo 2 adalah 0,95 , trafo 3 adalah 0,95 , trafo 4 adalah 0,95 , trafo 5 adalah 0,95 , trafo 6 adalah 1,025, trafo 7 adalah 0,95 , trafo 8 adalah 0,95 , trafo 9 adalah 0,95 , trafo 10 adalah 0,95 , trafo 11 adalah 0,95 , trafo 12 adalah 0,95 , trafo 13 adalah 1,025 , trafo 14 adalah 0,975 , trafo 15 adalah 0,95 , trafo 16 adalah 0,95 , trafo 17 adalah 0,95 , trafo 18 adalah 0,95 , trafo 19 adalah 0,95 , trafo 20 adalah 0,95 , trafo 21 adalah 0,95 , trafo 22 adalah 0,95 , trafo 23 adalah 0,95 dan nilai rugi daya pada PT PJB indramayu berkurang dari 20,7946 MW menjadi 20,7901 MW dan setelah pemasangan Tap trafo, tegangan pada beberapa bus meningkat sesuai dengan batas yang ditetapkan yaitu antara 0,95 dan 1,05. Parameter-parameter yang digunakan untuk mendapatkan hasil rugi daya minimum adalah ukuran populasi 10 jumlah iterasi 300 , nilai $\mathrm{C} 1$ adalah 1 , nilai $\mathrm{C} 2$ adalah 2 , nilai $\theta_{\min }$ adalah 0,9 , nilai $\theta_{\max }$ adalah 0,4 . Setelah dilakukan pengoptimasian pengaturan tap trafo menggunakan metode PSO, nilai rugi daya pada PT PJB Indramayu berkurang dari 20,7946 MW menjadi 20,7894 MW.

\section{Referensi}

[1]. C. Batsyua and S. Handoko, "Analisis Pengaturan Tap Trafo Dan Penempatan Pembangkit Terdistribusi ( DG ) Untuk Mereduksi Jatuh Tegangan Dan Rugi Daya Di Gi Purwodadi.", Skripsi Jur. Tek. Elektro Univ. Diponegoro,2016

[2]. Turan Gonen, “ Electrical Power Distribution System Engineering”, Mc Grow Hill Book, 1986.

[3]. Suhadi and T.Wrahatnolo, " Teknik Distribusi Tenaga Listrik", 1st ed, Jakarta, 2008.

[4]. O. Lawang, "Optimasi Load Tap Changing Transformer Menggunakan Algoritma Genetik Guna Meminimalisasi Rugi Daya Transmisi," Skripsi Jur. Tek. Elektro Univ. Diponegoro, 2003.

[5] T. Sukmadi, A. D. Wardhana dan M. A. Riyadi, "Optimization of gas turbine power plant economic dispatch using Cuckoo Search Algorithm method," 2017 4th International Conference on Information Technology, Computer, and Electrical Engineering (ICITACEE), Semarang, 2017, hal. 131-135

[6] Zhang, Wen, dan Yutian Liu. "Reactive power optimization based on PSO in a practical power system." Power Engineering Society General Meeting, 2004. hal. 239-243.

[7]. Tito Wiratsongko, “Optimisasi Penempatan Kapasitor Bank Untuk Mereduksi Rugi Daya Menggunakan Flower Pollination Algorithm Pada Jaringan Auxiliary Load PT.PJB Pembangkitan Indramayu 3x330 Mw," Skripsi Jur. Tek. Elektro Univ. Diponegoro, 2017. 


\section{TRANSMISI, 20, (3), JULI 2018, p-ISSN 1411-0814 e-ISSN 2407-6422}

[8]. L. Siregar, "Pengujian Tap trafo Transformator Distribusi 20 kV," Penelit. Univ. HKABP Nommensen, 2013.

[9]. Qin, Hengsi, J.W. Kimball, dan GK. Venayagamoorthy. "Particle swarm optimization of high-frequency transformer." IECON 2010-36th Annual Conference on IEEE Industrial Electronics Society, 2010, hal. 29142919
[10]. B.Santosa, P.willy, “Metoda Metaheuristik - Konsep dan Implementasi.”, Surabaya, April, 2011. 